\title{
Pores dominate ice nucleation on feldspars.
}

\author{
E. Pach ${ }^{\dagger}$ A. Verdaguer ${ }^{\dagger *}$ \\ Institut de Ciència de Materials de Barcelona ICMAB-CSIC, Campus de la UAB, \\ E-08193 Bellaterra, Spain \\ *averdaguer@icmab.es
}

\begin{abstract}
Feldspar particles have been considered to be responsible of a large proportion of the ice nucleation particles present in clouds. In this work, using environmental scanning electron microscopy (E-SEM), we investigated ice nucleation on different faces of feldspar minerals exposed to water vapor below water saturation conditions. Our experiments revealed that nucleation was dominated by natural micro-sized pores exposed at the surface of the mineral upon cleavage. Between 80 to $90 \%$ of the sites where ice crystals appeared in the nucleation experiments was related to a pore. Ice crystals appeared at the same sites and with the same orientation in consecutive nucleation experiments indicating an overimposed template from the surface to the ice crystallographic growth. Sequences of E-SEM images showed that ice growth inside pores starts with the filling of the pore and then the growth of the crystal outside the pore, as it's described by the pore condensation freezing theory to explain ice nucleation in porous materials exposed to humid air below saturation. Micro-sized pores are too large to satisfy the theoretical conditions for pore condensation freezing theory but high magnification SEM images
\end{abstract}


revealed the presence of additional pores at the nanoscale inside the micro-sized pores. Our findings demonstrate that porosity in feldspar particles plays a key role in determining its ice nucleation efficiency in the deposition mode.

\section{INTRODUCTION}

The formation of ice, when and how water freezes, is still poorly understood, even though this is essential for understanding Earth's climate. ${ }^{1}$ Knowing more about the molecular mechanisms underlying these processes can help to build atmospheric and climate models with higher confidence. One of the key factors in ice nucleation is to understand how solid surfaces induce heterogeneous nucleation. ${ }^{2}$ Many different surface properties can have an impact on heterogeneous ice nucleation: structural matching between the surface and ice ${ }^{3}$, polarity at the surface $^{4}$, chemical groups exposed at the surface ${ }^{5}$, surface topography $y^{6,7}$ or water confinement ${ }^{8}$. Studies performed in cryogenic conditions at molecular level clearly indicate that the interaction of water molecules with the surface determines the ice structures that will be formed at the interface. $^{9,10}$ However, cryogenic temperatures can easily lead to situations where thermodynamic equilibrium is not reached, so that the results might not be transferable to ambient conditions. Studies on the interaction of water and ice with surfaces in ambient conditions have been restricted mainly to light microscopy ${ }^{11}$ and spectroscopy ${ }^{3}$ or scanning probe microscopy ${ }^{12,13}$. However, in the last two decades, advances in surface-sensitive techniques based 
on electron spectroscopy ${ }^{14}$ and microscopy ${ }^{15}$, that were traditionally limited to work in vacuum conditions, have allowed measurements at temperatures and pressures relevant to ice in ambient conditions. In this work, we take advantage of one of these techniques, environmental Scanning Electron Microscopy (E-SEM), to study ice nucleation on feldspar surfaces.

Studies of atmospheric ice nucleation induced by solid particles suggested that surfaces could exhibit a small number of active sites that determine the nucleating ability of an entire surface $^{16,17}$. Each site would have its own threshold of supersaturation or supercooling above which nucleation becomes probable and thus, the sites with the lowest thresholds would dominate nucleation ${ }^{18}$. K-rich feldspar has been identified as one of the most active atmospherically relevant ice-nucleating minerals ${ }^{19,20}$. Heterogeneous nucleation on feldspar samples has been recently studied from the interaction with the vapor ${ }^{15}$ and liquid phases ${ }^{21}$. In both cases, it was pointed out that steps and pores of the surface would be very active as icenucleation sites. Several decades ago, it was already suggested that ice nucleation from vapor may proceed by the formation of ice embryos within small pores or cracks, and that bulk crystals would emerge then from these when saturation of water vapor is sufficient ${ }^{22,23}$. This phenomenon, named pore condensation and freezing ${ }^{24}$, has recently been observed at mica steps ${ }^{7}$ and on porous silica particles ${ }^{25}$. From these results it has been concluded that pore condensation and freezing must be a dominant pathway for atmospheric ice nucleation below water saturation. Here, we demonstrate using E-SEM that nucleation from vapor below water saturation on feldspar surfaces is totally dominated by pores and that, as predicted by Fukuta ${ }^{22}$, bulk ice crystals emerge from them. 


\section{METHODS}

In this work we studied ice nucleation on orthoclase Feldspar sample from the Mt. Maloso region, Malawi that was cleaved along the natural (001) and (010) faces and left at room conditions for a few days. The cleavage lead to surfaces formed mainly by flat terraces and steps with the presence of numerous cracks and pores, as observed on SEM images (Figure 1a). Those pores showed sizes in the order of few microns with regular edges likely to be along well-defined crystallographic faces. Examination by atomic force microscopy (AFM) clearly revealed that what we called "pores" are very deep and they are actually pores and not a bunch of steps created upon cleavage (Figure 1b). AFM images also revealed terraces with a roughness between 4 and $15 \mathrm{~nm}$, far from being atomically flat. Energy-dispersive x-ray (EDX) mapping showed regions rich in different cations $\left(\mathrm{K}^{+}\right.$and $\left.\mathrm{Na}^{+}\right)$as it's shown in Figure $\mathrm{S} 1$. From the analysis of the EDX mapping we estimate that the ratio between $\mathrm{K}^{+}$and $\mathrm{Na}^{+}$was proximately $4: 1$. To study ice nucleation, the sample was introduced in the E-SEM (FEI Quanta 650F ESEM) at temperatures between $-22{ }^{\circ} \mathrm{C}$ and $-9{ }^{\circ} \mathrm{C}$. Then, water vapor was introduced in the chamber until a pressure of 100 to $150 \mathrm{~Pa}$ was reached, corresponding to a relative humidity $(\mathrm{RH})$ close to $90 \%$. No ice nucleation was observed under these conditions. Next, pressure was increased approaching water saturation until ice nucleation events were observed as well-defined hexagonal ice crystals appearing on the surface (Figure $2 \mathrm{a}$ and $2 \mathrm{~b}$ ). Decreasing of the pressure to the original starting value sublimed the crystals and they completely disappeared from the images. We call this process a nucleation cycle. We want to point out that in our experimental set-up we only change water pressure in the chamber for each nucleation cycle. Experimental conditions of supersaturation with respect to ice and water ${ }^{26}$ and peltier temperature of the different nucleation cycles performed are shown in Figure 2c. The points in the plot indicate the conditions of 
temperature and supersaturation under which ice was first observed while increasing water vapor pressure in the chamber. Nucleation cycles were performed sequentially in order to induce new nucleation events in the same area of the sample. A nucleation cycle took a few tens of minutes to be completed. Water vapor pressure was modified at rates from 1 to $10 \mathrm{~Pa}$ per minute, both when increasing or decreasing the pressure. Unless large amounts of ice conglomerates were formed on the surface, complete sublimation of ice crystals at low pressure was observed in a timescale of 10 minutes or lower.

\section{RESULTS AND DISCUSSION}

When we performed nucleation cycles in the same region we found that sites where ice nucleation was observed consistently repeated from one cycle to another. This can be observed in Figure 3, where nucleation sites of two different pressure cycles (Figure 3a and 3b) were compared (Figure 3c). Although, new nucleation sites appeared in the second cycle, most of the sites showing a nucleation event in the first cycle induced again a nucleation in the second cycle. In addition to that, we found that nucleation sites were totally dominated by pores. We considered that a nucleation took place on a pore when the ice crystal is directly observed to begin inside a pore or when the area of the feldspar surface covered by the ice crystal in the first frame that the ice crystal appears contains a micron size pore. The density of such pores is low enough to distinguish when an ice crystal if formed on a pore and when not. Counting the different nucleation sites of several experiments we found that between 80 to $90 \%$ of the crystals were formed on a pore or crack, around 5 to $15 \%$ at steps and only few of them on sites that didn't show any visible special topography (see as an example the graphs in Figure 3c corresponding to the two nucleation cycles as shown in Figure 3a and 3b). 
The high reproducibility of the sites where ice nucleation happened at each cycle allowed us to center E-SEM images on some of the pores that showed high efficiency as ice nucleation sites. Then, in these high-resolution E-SEM images, nucleation occurring inside the pores and then emerging from it could be observed if the water pressure was increased slowly. In Figure 4 sequences of images from three different nucleation cycles of ice crystals growing from the inside of pores are shown. In the images ice crystals seem to first fill the pores and then emerge from them. Thus, observing nucleation events in different sites and cycles we could conclude the following: a) Most of the nucleation events happen at pores, b) Ice nucleation sites are very specific and crystals are formed in exactly the same position form one cycle to another (within the image resolution, in the order of $1 \mu \mathrm{m}), \mathrm{c}$ ) Ice crystals seem to first fill the pores and then emerge from them, d) Ice crystal grown form exactly the same location showed the same orientation of the crystal from one nucleation cycle to another. This last finding can be better observed in Figure 5, where two consecutive nucleation events named cycle I and cycle II are shown for the same area of the sample. It can be observed that some crystals that appear on both cycles (colored with the same color gradient) showed exactly the same orientation. More nucleation events from within the pores can be observed in Figure 6a, in that case up to three different crystals grew from the same pore: three different ice nucleation sites inside the pore are observed in cycle I, two nucleation sites in cycles II, and III and only one in cycle IV.

Previous E-SEM studies of ice nucleation on orthoclase alkali feldspar found that nucleation of ice from vapor induces a specific orientation of the hexagonal ice crystal, characteristic for each face $^{15}$. In this previous work, on the (001) face, it was found that the basal face of ice crystals was parallel to this (001) face and with all the crystals with the same rotational orientation with 
respect of the $\mathrm{c}$ axis of the crystal. In our experiments, we found the same predominant orientation on the (001) face (see Figure 2a) although other orientations were always present. On the contrary, on the (010) face several orientations were found (see Figure $2 b$ ). Despite the different orientations observed, as shown in Figure 5, crystals grown from the same site showed exactly the same orientation for each consecutive cycle, indicating that ice crystal structure is induced by the substrate. A statistical analysis of the orientation of all the crystals observed revealed preferential orientations for crystal growth with the basal plane parallel to the surface. In Figure 6a, an example of ice crystals with different orientations grown on the (010) face is shown. The orientation of around one hundred crystals on different regions of the sample was measured as the angle formed by one of the prismatic faces of the ice crystals and the (001) direction of the feldspar, as shown in the scheme in Figure 6b. Three preferential orientations appear in the histogram created from these measurements (Figure 6c) that would correspond to crystals oriented with one prismatic face parallel to the (001) face and one prismatic face perpendicular to the (100) face or to the mirror image of the (100) direction, i.e. the (10-1) direction, as shown in the scheme in Figure 6b. On the other hand, crystals showing orientations with the basal plane not parallel to the surface didn't show any preferential orientation as revealed by an equivalent statistical analysis (See Figure S2 in the supplementary information).

Our findings indicate that pores are the most efficient sites inducing ice nucleation in feldspar when in undersaturation conditions, according to the high percentage of nucleation events occurring at pores if compared with events occurring at other sties such as steps or flat terraces. Efficiency of pores as ice nucleation sites was already established indirectly in experiments on different feldspar powders. ${ }^{27}$ In those studies, it was concluded that the presence of nanoscale features such as pores was the key factor in determining the activity of a kind of feldspar. Those 
nanoscale features can be formed on feldspars due to strain induced by the phase separation into $\mathrm{Na}$ and $\mathrm{K}$ rich regions ${ }^{27,28}$. In fact, our EDAX images revealed phase separation of $\mathrm{Na}$ and $\mathrm{K}$ rich regions on pores showing high nucleation efficiency (Figure S1). The reason that could make a pore more efficient for ice nucleation could be chemical, for example a specific distribution of $\mathrm{OH}$ groups that could exist only in the walls of the pores ${ }^{15,28}$ or morphological, for example due to water confinement inside the pores.

As mentioned above, it has been predicted theoretically that nucleation in pores often proceeds via two steps: condensation in the pore and pore filling, and nucleation out of the pores ${ }^{23,25,29}$. Actually, at low temperatures, it has been observed that the limiting step is not nucleation but a free energy barrier associated with the emergence of ice from the pore to become a bulk phase ${ }^{30}$. Although, our micro-sized pores are much larger that critical radius for ice ${ }^{7}$, in the order of a few $\mathrm{nm}$, we did observe this two step process in some pores showing sizes below $5 \mu \mathrm{m}$ in which a filling of the pore by rather an amorphous shape crystal is observed before a well defined hexagonal crystal starts to grow outside the pore (see Figure 4). Unfortunately, the low rate in our image recording, in the order of 1 frame per second, didn't allow us to follow in detail the complete evolution. These pores are characteristics of the specific microtextures present in alkali feldspar $^{31,32}$. Those microtextures could contain nanoscale features, such as nanotunnels ${ }^{33}$ that would be of the length scale of the ice critical nucleus and thus they may stabilize it as predicted by classical nucleation theory ${ }^{27}$. The presence of nano-sized porosity and features inside the micro-sized pores could be the morphological factor that would explain the presence of ice nucleation sites inside the pores, since it would be specific from the pores and not found in other topological features created during cleavage such us steps. We also have to consider that when pressure is lowered in a nucleation cycle ice crystals melt and completely disappear from the 
SEM images, nevertheless some ice can remain inside the pores and thus act as embryo for a new nucleation cycle. This phenomenon has been proposed as a pre-activation method for ice nucleation particles ${ }^{34,35}$. That would explain why a nucleation cycle generally shows ice crystals appearing at the same sites as previous cycles and crystals appearing at new sites. If the substrate was warmed up above ice melting point between cycles the new nucleation event showed a mixture of new nucleation sites and nucleation sites already observed before the warming. The orientation of the crystals growth from "old" nucleation sites was kept only in some cases and the experiment was not conclusive in elucidating which of the two phenomena is responsible of the ice crystal orientation. One thing that should be considered is that warming the sample above the melting point reduces $\mathrm{RH}$ in the chamber (sometimes below 40\%) and thus desorbs also liquid water from the surface. Water adsorption on the surface was not homogeneous when the temperature was lowered again. In general, water molecules adsorb on surfaces forming monolayers or patches ${ }^{13}$ that depend strongly on surface morphology ${ }^{12}$, i.e. water can absorb preferentially on different pores or even on different sites inside the pore and thus nucleation can take place on different sites after warming up and cooling down the sample again. In the normal nucleation cycles described in the methods section RH in the chamber changed only from $\sim 90 \%$ to just before saturation and no important differences on where water is adsorbed is expected.

Although, no pores or features in the order of a few $\mathrm{nm}$ could be observed, high magnification SEM images taken in vacuum conditions revealed the presence of morphological features such as pores (probably the tunnels mentioned above) and cracks with dimensions below $100 \mathrm{~nm}$ inside the micro-sized pores that were discovered to act as highly efficient ice nucleation sites (see Figure 7). To obtain more information on the pores morphology AFM imaging of some of the most efficient pores was performed (Figure S3). No better resolution of the nano-sized 
tunnels observed in SEM could be obtained using AFM. Nevertheless, AFM revealed that pores were very deep, showing at least an aspect ratio vertical to horizontal of 1:1, i. e. they are as deep as wide and revealing a complex morphology that could contain many different shapes able to act as an ice nucleation site. ${ }^{25}$

On the other hand, the fact that ice crystals growth on a specific site inside the pore (see Figures 4 and 5) showed the same orientation on each cycle confirms that even if nucleation happens by pore condensation, making them the most effective nucleation site, nucleation is generated on a specific atomic arrangement of atoms at the surface that imposes the growth of the ice crystal with a specific orientation. However, our results, with multiple orientations on the same face, indicate that the imposition of the crystal orientation by the feldspar substrate should be more complex than just a direct relationship with the exposed crystallographic face as described in previous works. ${ }^{15}$

\section{CONCLUSIONS}

In summary, we have investigated ice nucleation on feldspar surfaces in contact with humid air below water saturation with E-SEM. Our observations revealed that a large majority of the ice crystals appearing in the nucleation events happened on micro-sized pores, known to be characteristics of some feldspars, present at the cleaved surface. Sequential nucleation events induced by cycles of increasing and decreasing water vapor pressure revealed that nucleation happens on sites that showed nucleation before and that crystals grown from the same site always appeared with the same orientation with respect to the feldspar surface. Experiments also confirmed that nucleation starts inside the pore, fills the pore showing an amorphous morphology 
and then grows outside the pore following hexagonal ice structure. This finding resembles what's predicted by the pore condensation and freezing theory where condensation of water inside the pore and filling of the pore is expected to happen at conditions below water saturation followed by ice nucleation and growth of the crystal outside the pore. This theory should be limited only to nanoscale pores. SEM high magnification images revealed the presence of pores at the nanoscale inside the micro-sized pores where ice nucleation was observed that could take account on the size limitation of the theory. Finally, we don't reject the possibility of ice surviving inside the pores, even if not visible in the SEM images when pressure is lowered. It would mean that feldspar could be pre-activated ${ }^{34}$ in order to enhance its nucleation efficiency although more experiments would be needed to confirm this point.

\section{ASSOCIATED CONTENT}

\section{Supporting Information.}

A PDF file containing:. EDAX images of $\mathrm{Na}$ and $\mathrm{K}$ distribution on the surface. Statistical analysis of crystals on the (010) surface. 3-D AFM images of pores.

\section{ACKNOWLEDGMENT}

We acknowledge the MINEICO project MAT2016-77852-C2-1-R (AEI/FEDER, UE) and the "Severo Ochoa" Program for Centers of Excellence in R\&Db(SEV-2015-0496). 


\section{FIGURE CAPTIONS:}

a)
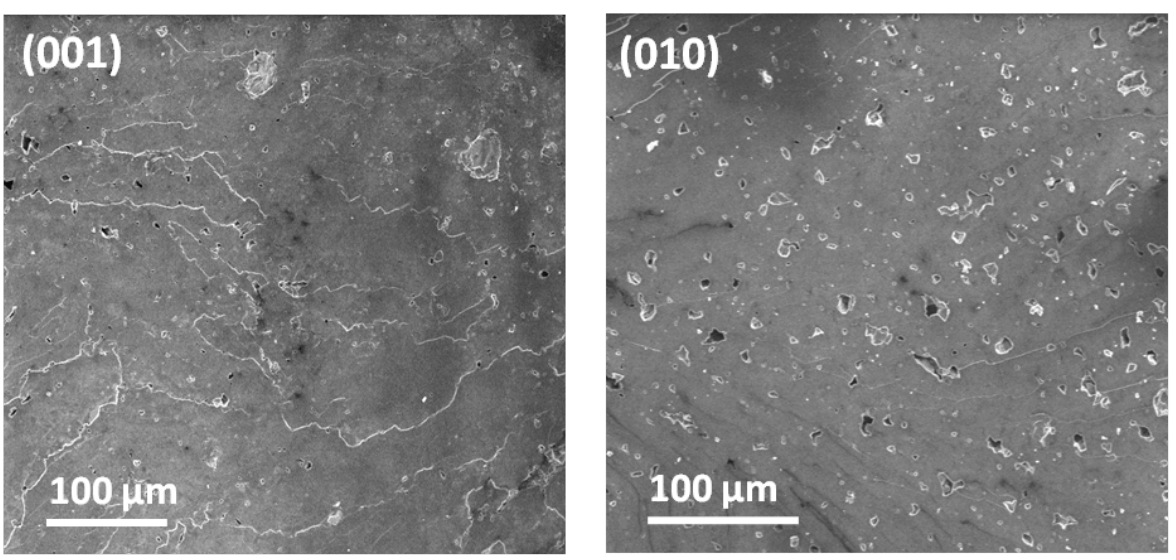

b)
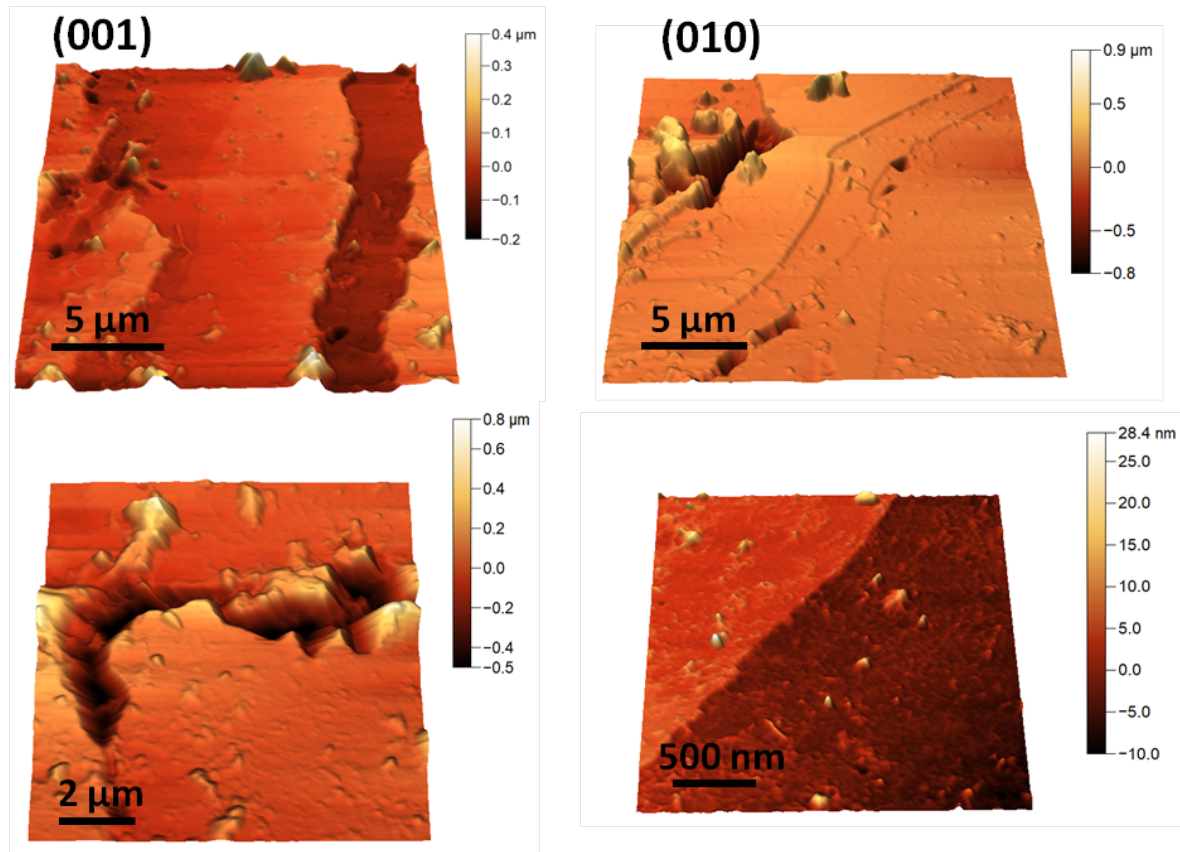

Figure 1: a) SEM images of the cleaved (001) and (010) surfaces of the feldspar sample. and b) Amplitude modulation Atomic Force Microscopy (AM-AFM) images of the cleaved (010) and (001) surfaces of the feldspar sample: a) (010) surface; left: $20 \times 20 \mu \mathrm{m}$ showing some terraces, steps and pores, right: $2.5 \times 2.5 \mu \mathrm{m}$ of a terraces and a step. b) (001) surface; left: $20 \times 20 \mu \mathrm{m}$ showing terraces, steps and pores, right: $10 \times 10 \mu \mathrm{m}$ image of a crack. Roughness of flat terraces from AFM images show values ranging from 5 to $15 \mathrm{~nm}$ depending on the region. Steps 
measured from the images were a few nanometers height. Images are created from a 3D rendering of the raw AFM data using the free software Gwyddion with a color scale to indicate vertical position and false illumination.

a)

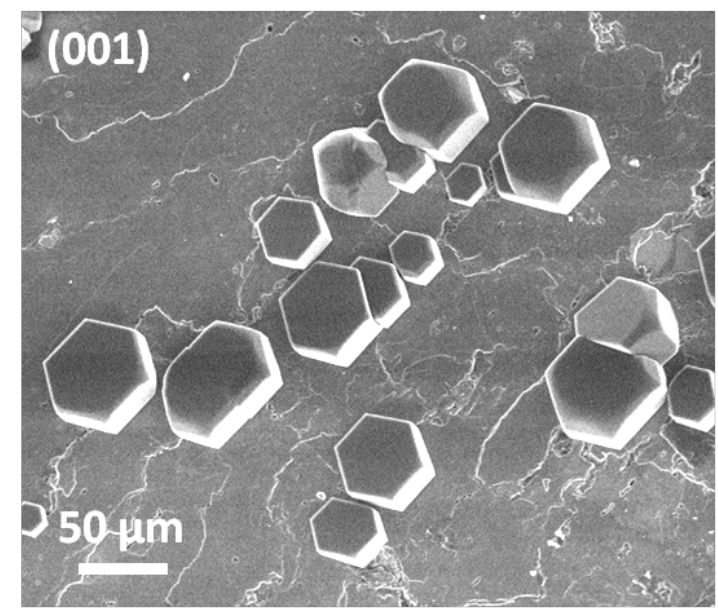

b)

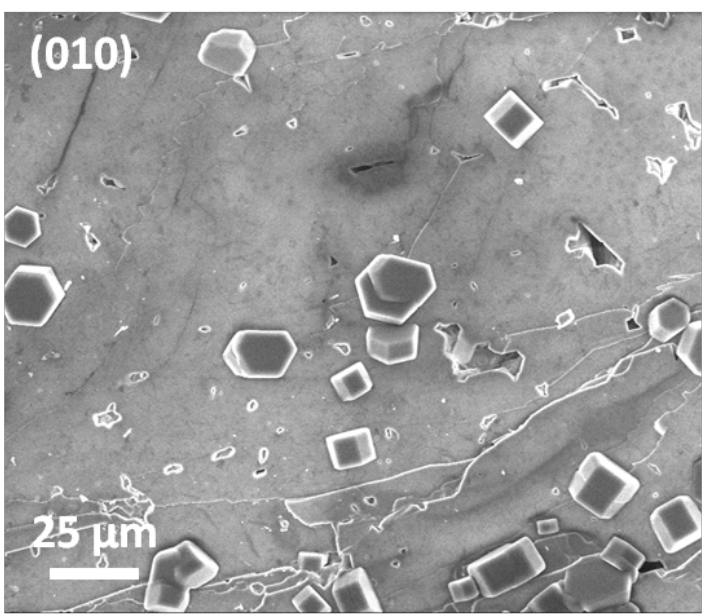

c)

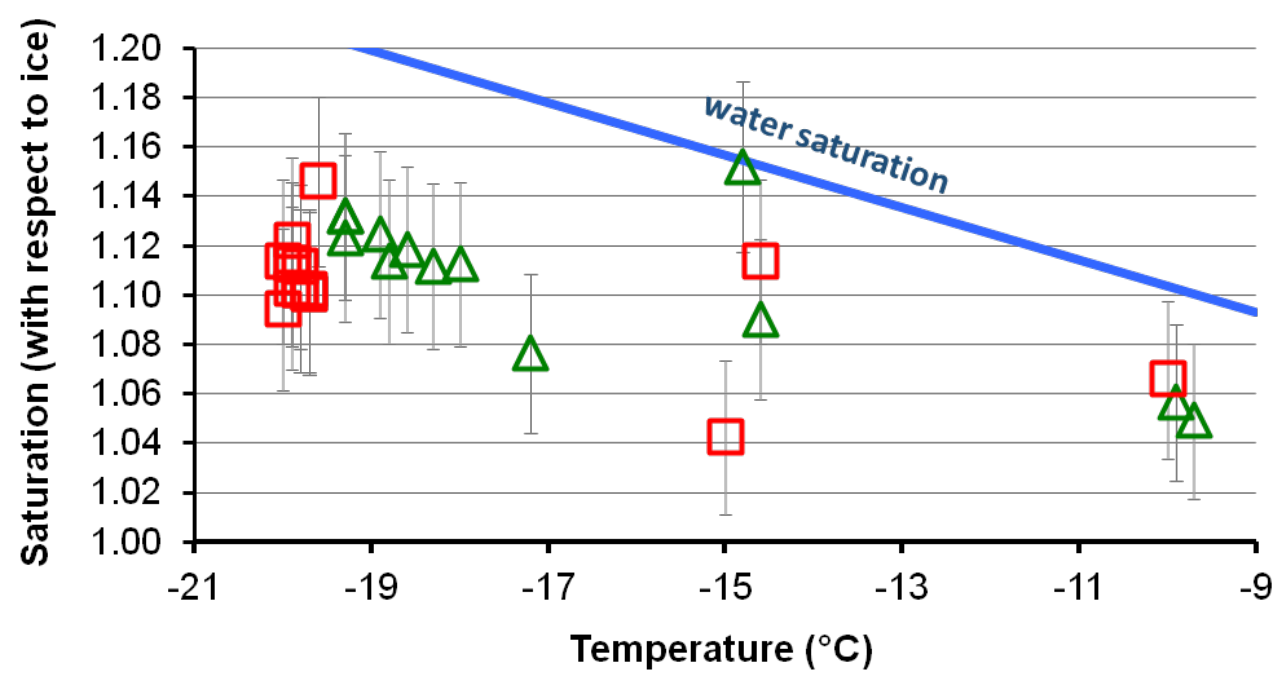

Figure 2: a) and b) SEM images of ice crystals growth on the (001) (a) and (010) (b) face of an orthoclase feldspar crystal at $-20^{\circ} \mathrm{C}$. c) Saturation with respect to ice and temperature conditions of ice nucleation observed in the different experiments performed on the feldspar crystal. Green 
triangles correspond to the (001) face and red squares to the (010) face. Error in the $\mathrm{x}$-axis is $\pm 0.2^{\circ} \mathrm{C}$.

a)

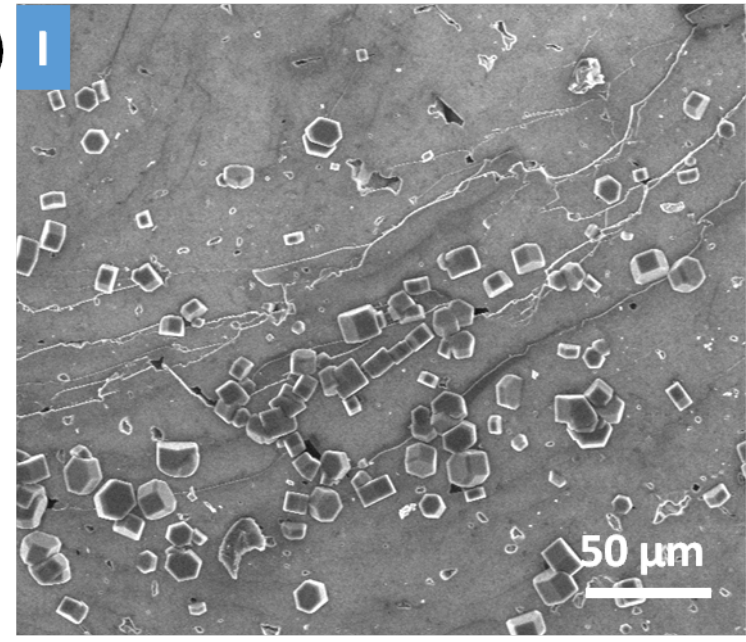

c)

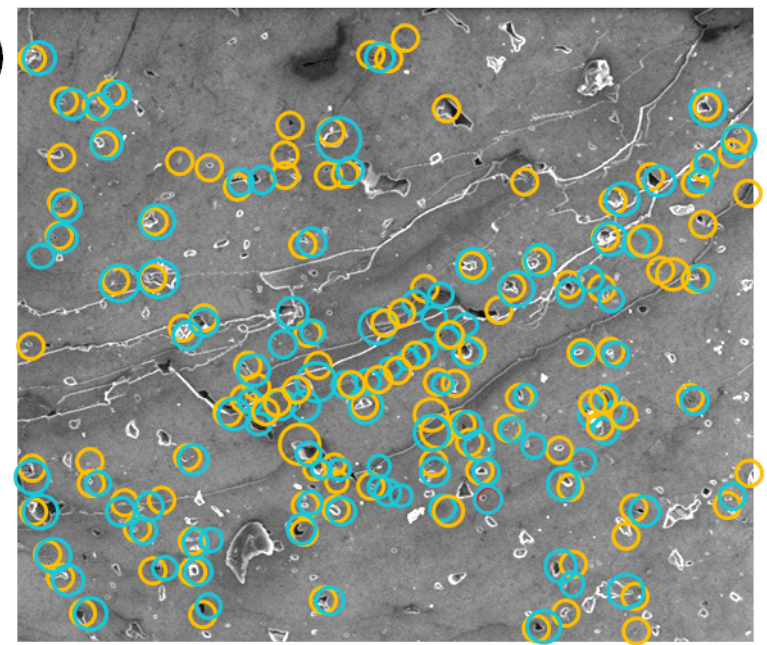

b)

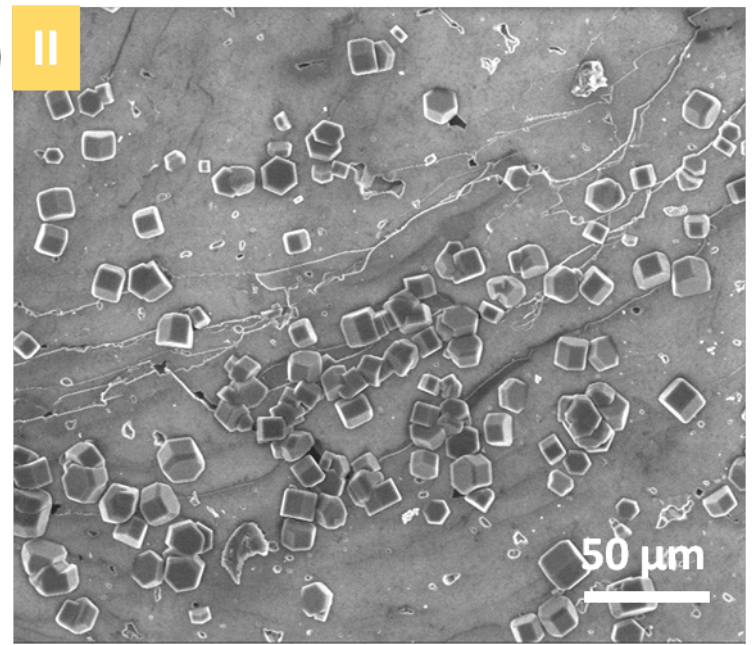

d)

$\square$ 1st cycle 2nd cycle

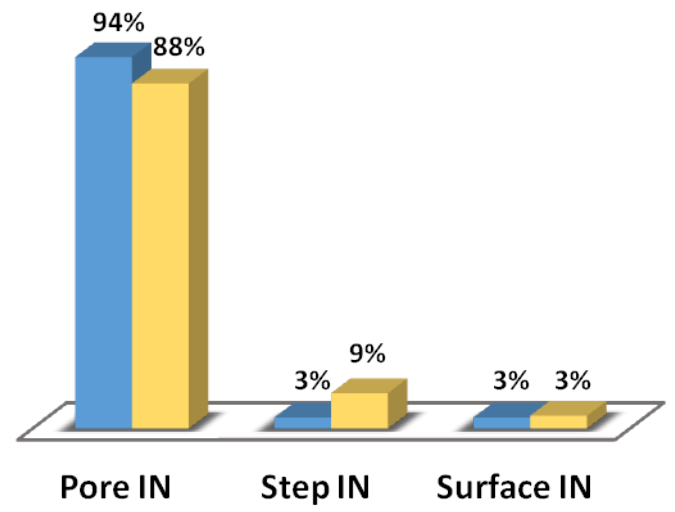

Figure 3: a) and b) SEM images of two consecutive nucleation cycles (I and II) on the same region of the feldspar (010) face at $-20^{\circ} \mathrm{C}$. Ice nucleation sites for each cycle are compared in c), blue circles corresponding to cycle I and orange circles to cycle II. d) Percentages of ice crystals that appear from pores, steps and non-specific site for cycle I and II. 

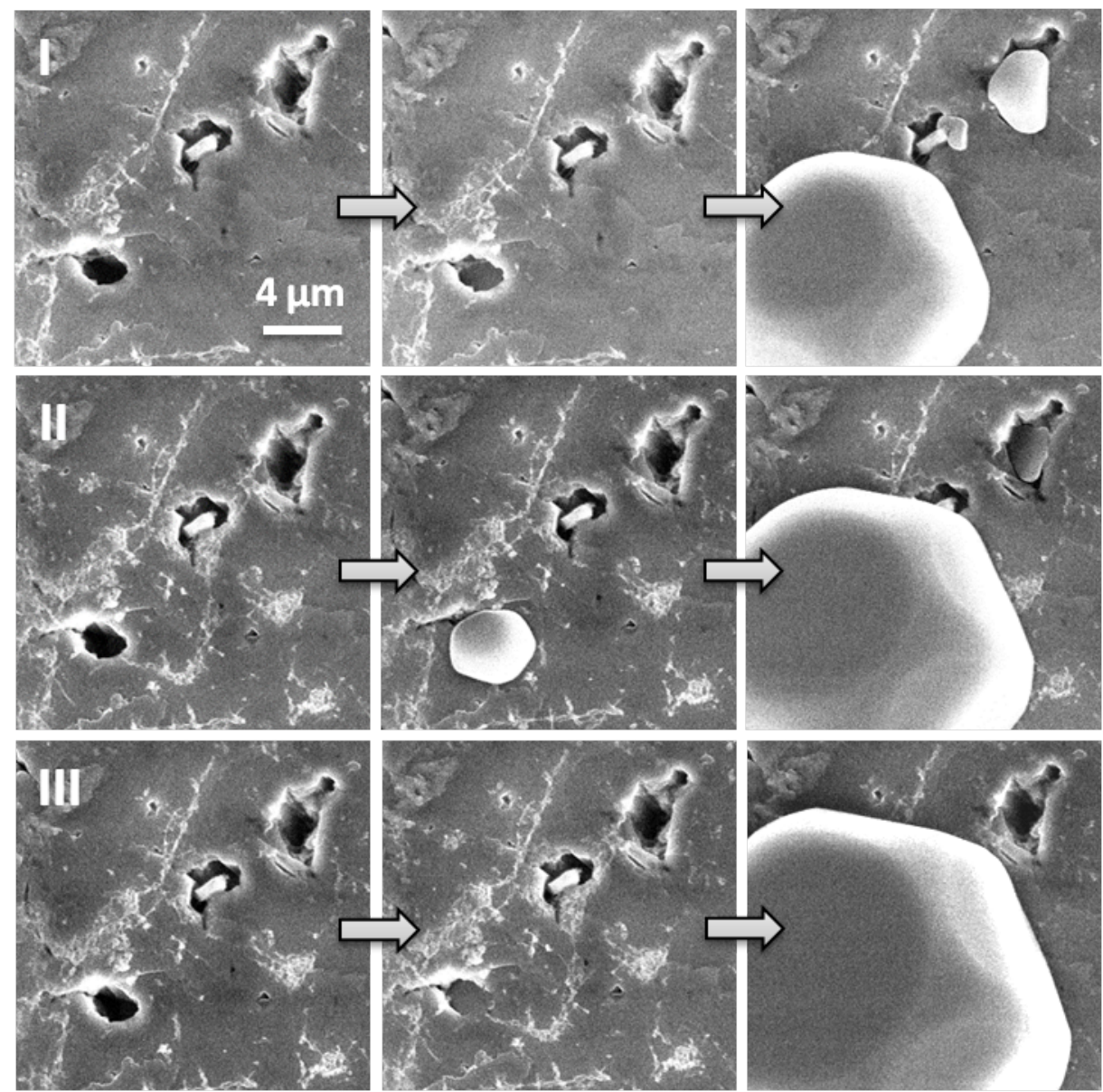

Figure 4: SEM images of three nucleation cycles (I, II and III) show that ice forms inside the pores, filling them and them emerge from them. 


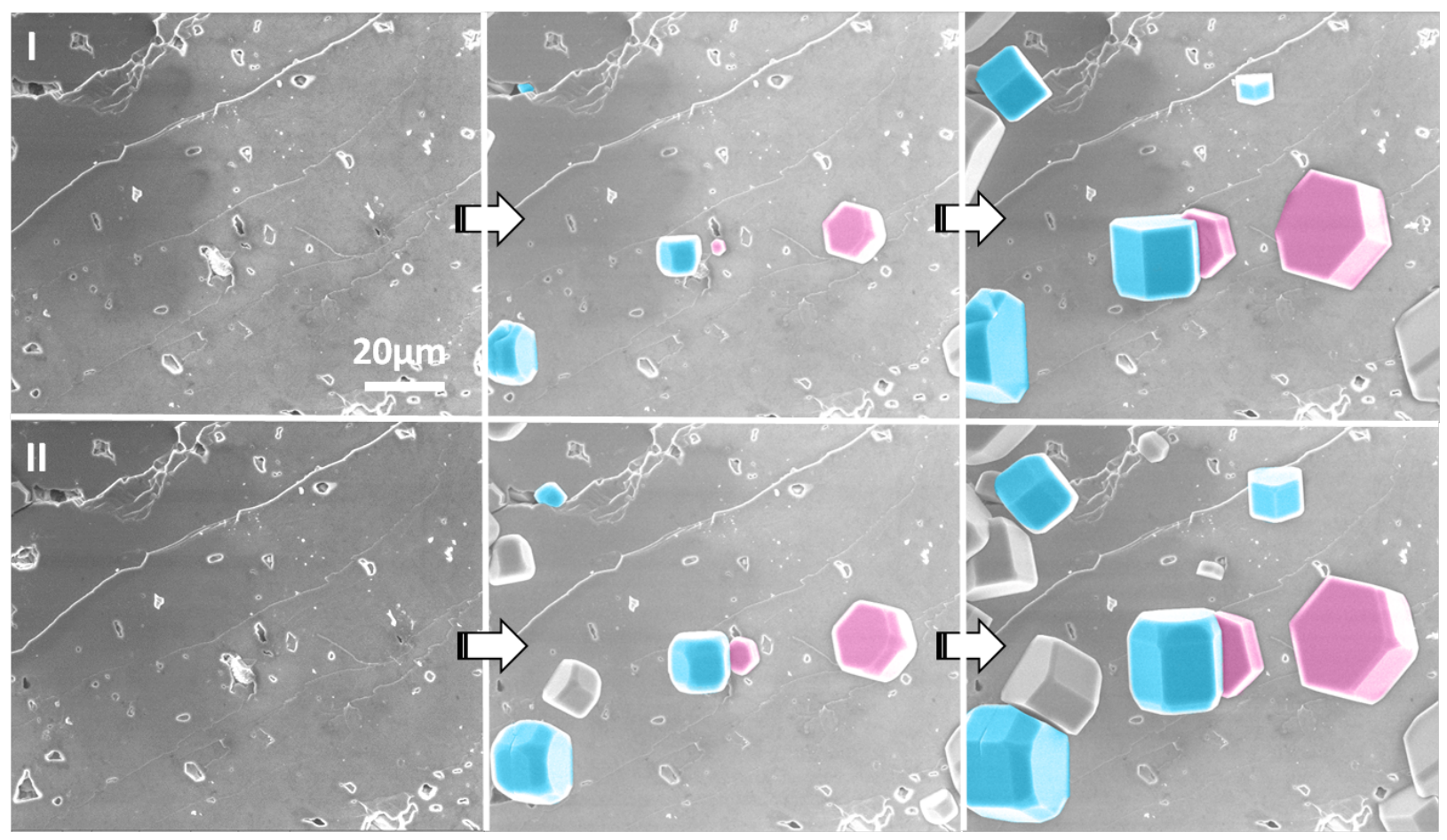

Figure 5: SEM images of two consecutive nucleation cycles (I and II) show that crystals grown from the same sites show the same orientation in each cycle. Coloring of crystals is just an eye guide to identify crystals grown from the same site. 
a)

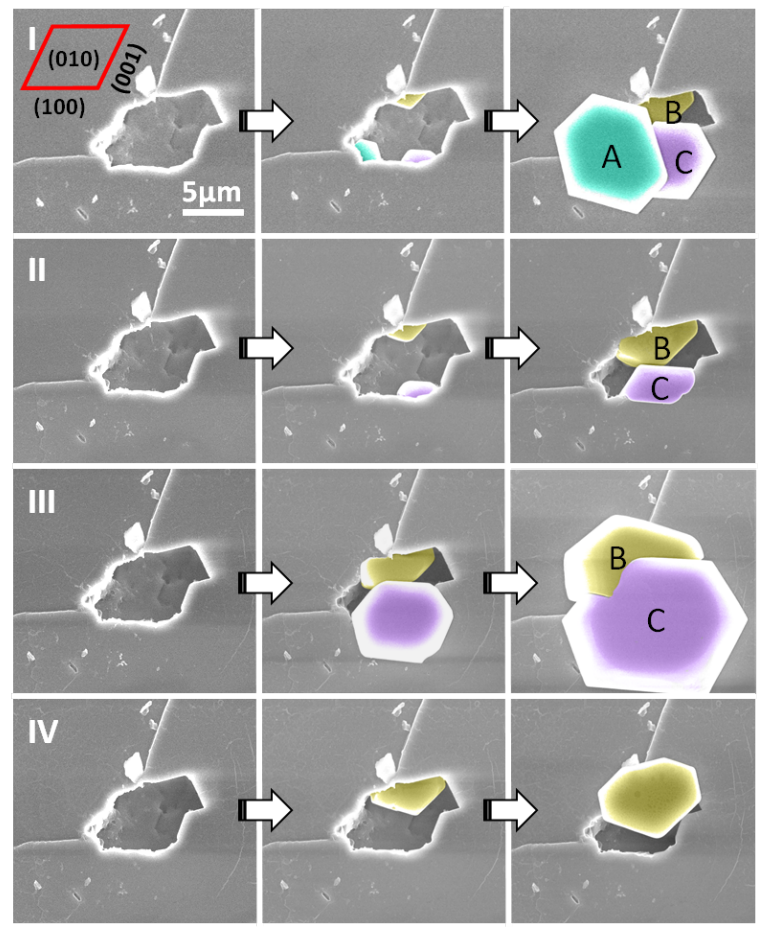

b)
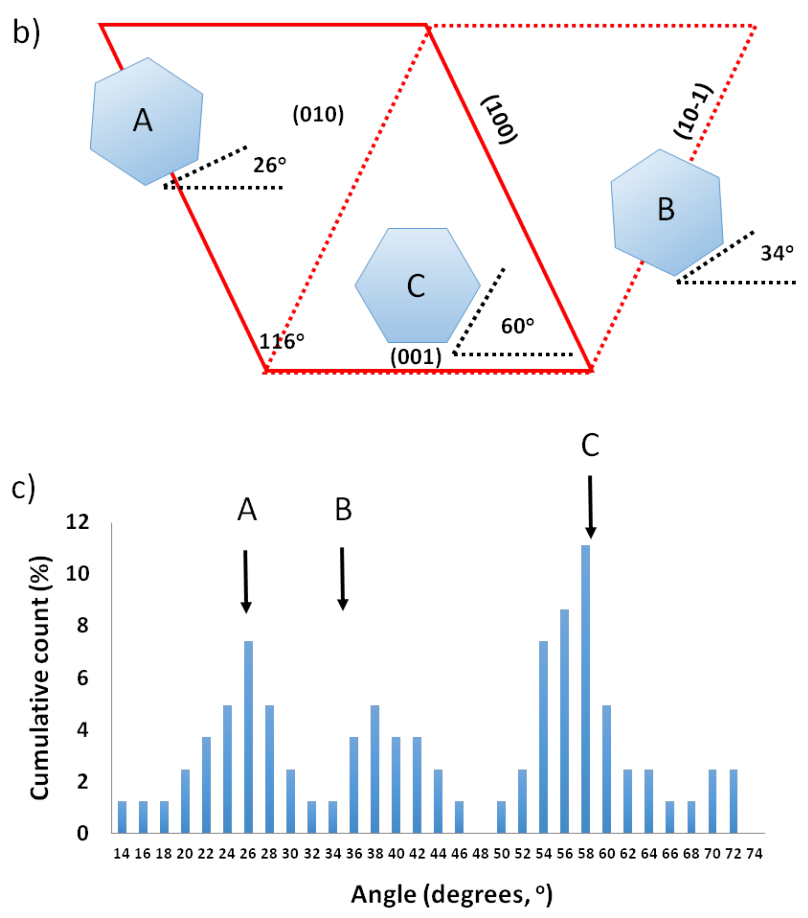

Figure 6: a) SEM images of four nucleation cycles (I, II, II, IV) from a single pore on the (010) face of the feldspar crystal. Crystal grown from the exact site inside the pore shows always the same orientation, however crystals grown from different sites inside the pore can show different orientations. b) Histogram of the orientations of the crystals showing the basal face co-planar with the surface. The preferential orientations are observed. Those orientations correspond to ice crystals with a prismatic face parallel to the feldspar (001) direction or perpendicular to the (010) direction and it mirror image (10-1) as shown in the scheme in b). 
a)

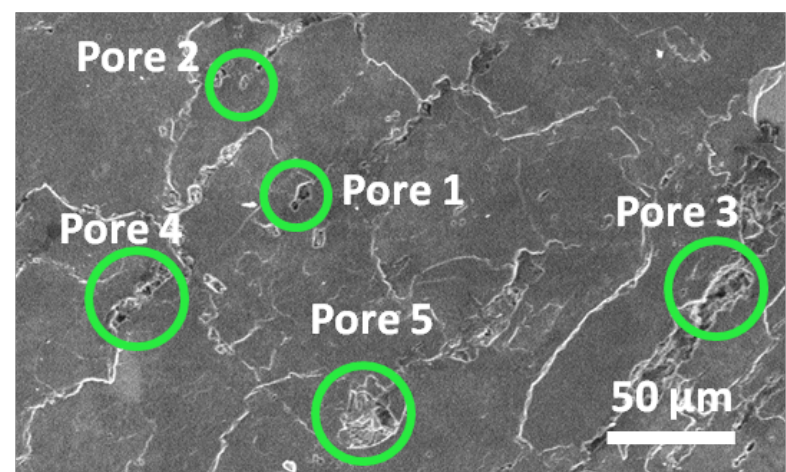

b)

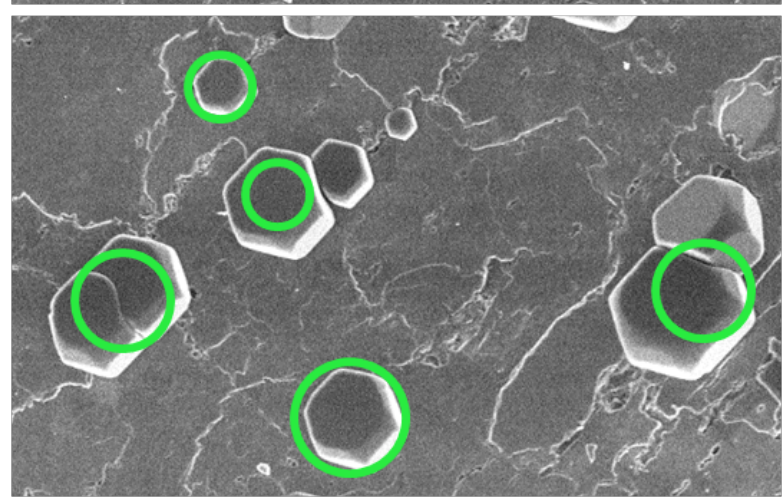

c)
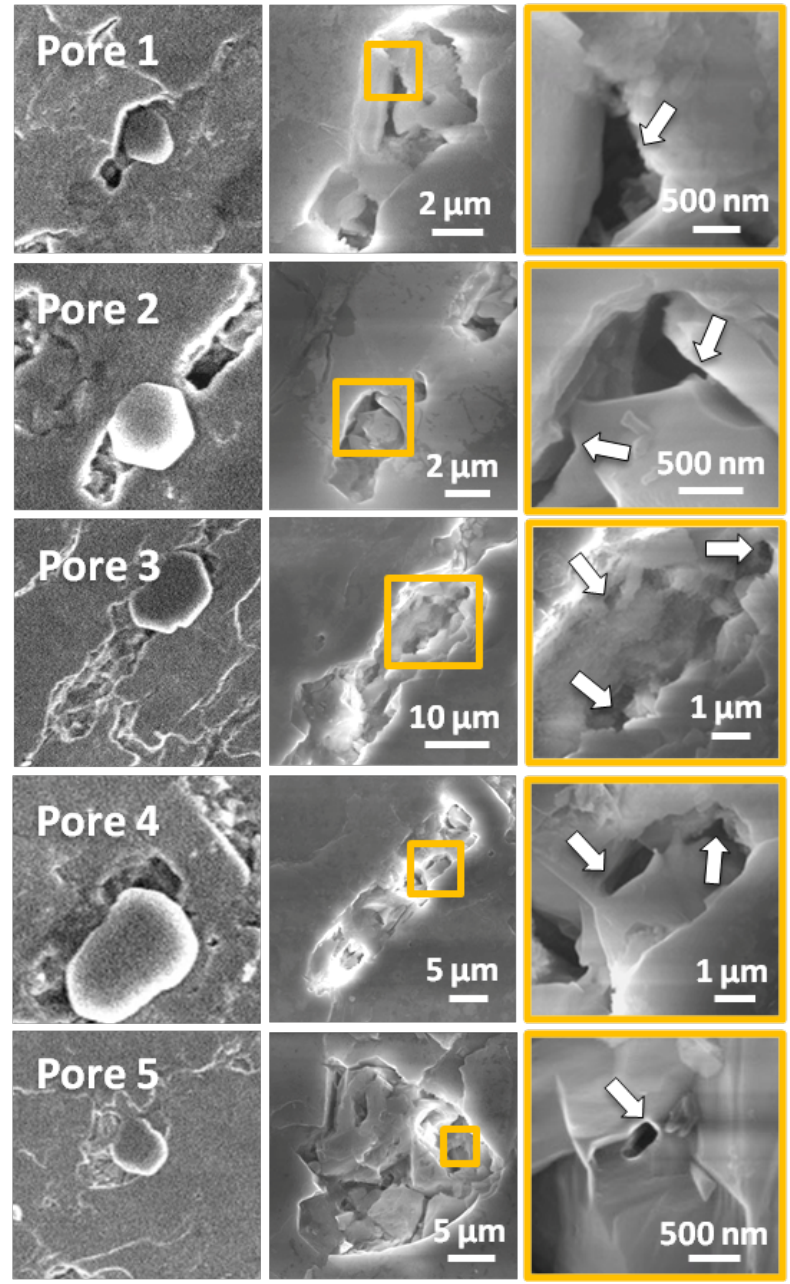
Figure 7: a) SEM images of ice crystals grown from pores on the (001) face of the feldspar crystal. b) High resolution images of the site where nucleation begins revealed the presence of cracks, and pores in the order of $100 \mathrm{~nm}$ and lower that can correspond to known microtextures of feldspar crystals.

\section{REFERENCES}

(1) Bartels-Rausch, T.; Bergeron, V.; Cartwright, J. H. E.; Escribano, R.; Finney, J. L.; Grothe, H.; Gutiérrez, P. J.; Haapala, J.; Kuhs, W. F.; Pettersson, J. B. C.; et al. Ice Structures, Patterns, and Processes: A View across the Icefields. Rev. Mod.Phys. 2012, 84 (2), 885-944. https://doi.org/10.1103/RevModPhys.84.885.

(2) Bartels-Rausch, T. Ten Things We Need to Know about Ice and Snow. Nature 2013, 494 (7435), 27-29. https://doi.org/10.1038/494027a.

(3) Ewing, G. E. Ambient Thin Film Water on Insulator Surfaces. Chem. Rev. 2006, 106 (4), 1511-1526. https://doi.org/10.1021/cr040369x.

(4) Ehre, D.; Lavert, E.; Lahav, M.; Lubomirsky, I. Water Freezes Differently on Positively and Negatively Charged Surfaces of Pyroelectric Materials. Science 2010, 327 (5966), 672-675. https://doi.org/10.1126/science.1178085.

(5) Pedevilla, P.; Fitzner, M.; Michaelides, A. What Makes a Good Descriptor for 
Heterogeneous Ice Nucleation on OH-Patterned Surfaces. Phys. Rev. B 2017, 96 (11), 115441. https://doi.org/10.1103/PhysRevB.96.115441.

(6) Bi, Y.; Cao, B.; Li, T. Enhanced Heterogeneous Ice Nucleation by Special Surface Geometry. Nat. Commun. 2017, 8, 15372. https://doi.org/10.1038/ncomms15372.

(7) Campbell, J. M.; Meldrum, F. C.; Christenson, H. K. Observing the Formation of Ice and Organic Crystals in Active Sites. Proc. Natl. Acad. Sci. U. S. A. 2017, 114 (5), 810-815. https://doi.org/10.1073/pnas.1617717114.

(8) Verdaguer, A.; Segura, J. J.; Lopez-Mir, L.; Sauthier, G.; Fraxedas, J. Communication: Growing Room Temperature Ice with Graphene. J. Chem. Phys. 2013, 138, 121101.https://doi.org/10.1063/1.4798941.

(9) Verdaguer, A.; Sacha, G. M.; Bluhm, H.; Salmeron, M. Molecular Structure of Water at Interfaces: Wetting at the Nanometer Scale. Chem. Rev. 2006, 106 (4), 1478-1510. https://doi.org/10.1021/cr0403761.

(10) Shimizu, T. K.; Maier, S.; Verdaguer, A.; Velasco-Velez, J.-J.; Salmeron, M. Water at Surfaces and Interfaces: From Molecules to Ice and Bulk Liquid. Prog. Surf. Sci. 2018, 93 (4), 87-107. https://doi.org/10.1016/J.PROGSURF.2018.09.004.

(11) Pach, E.; Rodriguez, L.; Verdaguer, A. Substrate Dependence of the Freezing Dynamics of Supercooled Water Films: A High-Speed Optical Microscope Study. J. Phys. Chem. B 2018, 122 (2), 818-826. https://doi.org/10.1021/acs.jpcb.7b06933.

(12) Cardellach, M.; Verdaguer, A.; Santiso, J.; Fraxedas, J. Two-Dimensional Wetting: The 
Role of Atomic Steps on the Nucleation of Thin Water Films on BaF2 (111) at Ambient Conditions. J. Chem. Phys. 2010, 132 (23), 234708. https://doi.org/10.1063/1.3456698.

(13) Santos, S.; Verdaguer, A. Imaging Water Thin Films in Ambient Conditions Using $\begin{array}{llllll}\text { Atomic } & \text { Force } & \text { Microscopy. } & \text { Materials. } & \text { 2016, } & 9\end{array}$ https://doi.org/10.3390/ma9030182.

(14) Verdaguer, A.; Weis, C.; Oncins, G.; Ketteler, G.; Bluhm, H.; Salmero, M. Growth and Structure of Water on $\mathrm{SiO} 2$ Films on Si Investigated by Kelvin Probe Microscopy and in Situ X-Ray Spectroscopies. Langmuir 2007, 23 (19), 9699-9703. https://doi.org/10.1021/la700893w.

(15) Kiselev, A.; Bachmann, F.; Pedevilla, P.; Cox, S. J.; Michaelides, A.; Gerthsen, D.; Leisner, T. Active Sites in Heterogeneous Ice Nucleation-the Example of K-Rich Feldspars. Science 2017, 355 (6323), 367-371. https://doi.org/10.1126/science.aai8034.

(16) Fletcher, N. H. Active Sites and Ice Crystal Nucleation. J. Atmos. Sci. 1969, 26 (6), 12661271. https://doi.org/10.1175/1520-0469(1969)026<1266:ASAICN>2.0.CO;2.

(17) Niedermeier, D.; Shaw, R. A.; Hartmann, S.; Wex, H.; Clauss, T.; Voigtländer, J.; Stratmann, F. Heterogeneous Ice Nucleation: Exploring the Transition from Stochastic to Singular Freezing Behavior. Atmos. Chem. Phys. 2011, 11 (16), 8767-8775. https://doi.org/10.5194/acp-11-8767-2011.

(18) Vali, G. Interpretation of Freezing Nucleation Experiments: Singular and Stochastic; Sites and Surfaces. Atmos. Chem. Phys. 2014, 14 (11), 5271-5294. https://doi.org/10.5194/acp$14-5271-2014$. 
(19) Atkinson, J. D.; Murray, B. J.; Woodhouse, M. T.; Whale, T. F.; Baustian, K. J.; Carslaw, K. S.; Dobbie, S.; O’Sullivan, D.; Malkin, T. L. The Importance of Feldspar for Ice Nucleation by Mineral Dust in Mixed-Phase Clouds. Nature 2013, 498 (7454), 355-358. https://doi.org/10.1038/nature12278.

(20) Yakobi-Hancock, J. D.; Ladino, L. A.; Abbatt, J. P. D. Feldspar Minerals as Efficient Deposition Ice Nuclei. Atmos. Chem. Phys. 2013, 13 (22), 11175-11185. https://doi.org/10.5194/acp-13-11175-2013.

(21) Holden, M. A.; Whale, T. F.; Tarn, M. D.; O’Sullivan, D.; Walshaw, R. D.; Murray, B. J.; Meldrum, F. C.; Christenson, H. K. High-Speed Imaging of Ice Nucleation in Water Proves the Existence of Active Sites. Sci. Adv. 2019, 5 (2), eaav4316. https://doi.org/10.1126/sciadv .aav4316.

(22) Fukuta, N.; Fukuta, N. Activation of Atmospheric Particles as Ice Nuclei in Cold and Dry Air. J. Atmos. Sci. 1966, 23 (6), 741-750. https://doi.org/10.1175/15200469(1966)023<0741:AOAPAI >2.0.CO;2.

(23) Koop, T. Crystals Creeping out of Cracks. Proc. Natl. Acad. Sci. U. S. A. 2017, 114 (5), 797-799. https://doi.org/10.1073/pnas.1620084114.

(24) Marcolli, C. Deposition Nucleation Viewed as Homogeneous or Immersion Freezing in Pores and Cavities. Atmos. Chem. Phys. 2014, 14 (4), 2071-2104. https://doi.org/10.5194/acp-14-2071-2014.

(25) David, R. O.; Marcolli, C.; Fahrni, J.; Qiu, Y.; Sirkin, Y. A. P.; Molinero, V.; Mahrt, F.; Brühwiler, D.; Lohmann, U.; Kanji, Z. A. Pore Condensation and Freezing Is Responsible 
for Ice Formation below Water Saturation for Porous Particles. Proc. Natl. Acad. Sci. 2019, 116 (17), 8184-8189. https://doi.org/10.1073/PNAS.1813647116.

(26) Murphy, D. M.; Koop, T. Review of the Vapour Pressures of Ice and Supercooled Water for Atmospheric Applications. Q. J. R. Meteorol. Soc. 2005, 131 (608), 1539-1565. https://doi.org/10.1256/qj.04.94.

(27) Whale, T. F.; Holden, M. A.; Kulak, A. N.; Kim, Y.-Y.; Meldrum, F. C.; Christenson, H. K.; Murray, B. J. The Role of Phase Separation and Related Topography in the Exceptional Ice-Nucleating Ability of Alkali Feldspars. Phys. Chem. Chem. Phys. 2017, 19 (46), 31186-31193. https://doi.org/10.1039/C7CP04898J.

(28) Harrison, A. D.; Lever, K.; Sanchez-Marroquin, A.; Holden, M. A.; Whale, T. F.; Tarn, M. D.; McQuaid, J. B.; Murray, B. J. The Ice-Nucleating Ability of Quartz Immersed in Water and Its Atmospheric Importance Compared to K-Feldspar. Atmos. Chem. Phys. Discuss. 2019, 1-23. https://doi.org/10.5194/acp-2019-288.

(29) Page, A. J.; Sear, R. P. Heterogeneous Nucleation in and out of Pores. Phys. Rev. Lett. 2006, 97 (6), 065701. https://doi.org/10.1103/PhysRevLett.97.065701.

(30) Campbell, J. M.; Christenson, H. K. Nucleation- and Emergence-Limited Growth of Ice from Pores. Phys. Rev. Lett. 2018, $120 \quad$ (16), 165701. https://doi.org/10.1103/PhysRevLett.120.165701.

(31) Parsons, I.; Fitz Gerald, J. D.; Lee, M. R. Routine Characterization and Interpretation of Complex Alkali Feldspar Intergrowths. Am. Mineral. 2015, 100 (5-6), 1277-1303. https://doi.org/10.2138/am-2015-5094. 
(32) Walker, F. D. L.; Lee, M. R.; Parsons, I. Micropores and Micropermeable Texture in Alkali Feldspars: Geochemical and Geophysical Implications. Mineral. Mag. 1995, 59 (396), 505-534. https://doi.org/10.1180/minmag.1995.059.396.12.

(33) Gerald, J. D. F.; Parsons, I.; Cayzer, N. Nanotunnels and Pull-Aparts: Defects of Exsolution Lamellae in Alkali Feldspars. Am. Mineral. 2006, 91 (5-6), 772-783. https://doi.org/10.2138/am.2006.2029.

(34) Wagner, R.; Kiselev, A.; Möhler, O.; Saathoff, H.; Steinke, I. Pre-Activation of IceNucleating Particles by the Pore Condensation and Freezing Mechanism. Atmos. Chem. Phys. 2016, 16 (4), 2025-2042. https://doi.org/10.5194/acp-16-2025-2016.

(35) Marcolli, C. Pre-Activation of Aerosol Particles by Ice Preserved in Pores. Atmos. Chem. Phys. 2017, 17 (3), 1595-1622. https://doi.org/10.5194/acp-17-1595-2017. 